\section{A hipótese do filtro afetivo e o constructo da motivação na aquisição de segunda língua: uma retomada crítica}

The affective filter hypothesis and the motivation construct within second language acquisition: a critical review

Gilberto Alves ARAÚJO (University of the Witwatersrand) gilbertoa.araujo@yahoo.com.br

Gizélia Maria da Silva FREITAS (UFPA) gizelia.freitas@gmail.com

Jorge Adriano Pires SILVA (UFPA) jorgejapsilva@gmail.com

Recebido em: 24 de jan. de 2019. Aceito em: 15 de maio de 2019.
ARAÚJO, Gilberto Alves; FREITAS, Gizélia Maria da Silva; SILVA, Jorge Adriano Pires. A hipótese do filtro afetivo e o constructo da motivação na aquisição de segunda língua: uma retomada crítica. Entrepalavras, Fortaleza, v. 9, n. 2, p. 492-512, maio-ago/2019.

Resumo: Este artigo discute as posições ocupadas pela hipótese do Filtro Afetivo e o construto da motivação nas pesquisas recentes em linguística aplicada, avaliando o potencial de ambos em abordar e explicar fenômenos na aquisição de segunda língua. Essa reflexão crítica acerca dos dois elementos ocorre a partir de quatro funções básicas de uma teoria: compreensão, transformação, predição e aplicação; sendo as três primeiras propostas por Mclaughlin (1988) e a última introduzida por nós. Nesse sentido, utilizamos a metodologia de revisão crítica de referenciais teóricos, abordando o período que compreende o fim do século XX e o início deste século. Nossas discussões nos permitem apontar que a hipótese do Filtro Afetivo contém problemas de formulação, predição, e correspondência a fenômenos empíricos, e outros de coerência interna, sem mencionar a excessiva abrangência e a vagueza conceptual, proposicional e prática. Essa hipótese também apresenta reduzido valor heurístico, o que leva pesquisadores a se concentrarem em outras proposições potencialmente mais produtivas. Já o constructo da motivação, não sendo uma propositura sistemática e explanatória, emerge como uma concepção altamente maleável, o que se mostra oportuno para múltiplos estudos, e também para a reorientação das pesquisas do foco Macro para o Micro.

Palavras-chave: Filtro Afetivo. Motivação. Ensino-Aprendizagem de Línguas. 
Abstract: This article discusses the positions the hypothesis of the Affective Filter and the construct of motivation occupy within recent researches of Applied Linguistics, assessing the potential that both of them have to approach and explain phenomena of second language acquisition. This critical reflection about the two elements is carried out according to four basic functions of a theory: understanding, transformation, prediction and application; being the first three components proposed by McLaughlin (1988) and the last introduced by the authors of this article. In this sense, we use the methodology of critical review on theoretical references, considering the period that goes from the end of the $20^{\text {th }}$ century to the beginning of this century. Our discussions allow us to indicate that the hypothesis of the Affective Filter contains problems of formulation, prediction, and correspondence to the empirical phenomena, in addition to other issues of internal coherence, not to mention its excessive inclusiveness and the conceptual, propositional and practical vagueness. This hypothesis also presents a reduced heuristic value, which might lead researchers to focus on other propositions that are potentially more productive. On the other hand, the construct of motivation, not being a systematic and explanatory proposal, emerges as a highly malleable conception, which seems to be conducive to multiple studies, and as a reorientation of researches within the area from the Macro to the Micro perspective.

Keywords: Affective Filter. Motivation. Language Teaching-Learning.

\section{Introdução}

O estudo das diferenças individuais (DIs) - dentro das quais se podem localizar os componentes afetivos da aprendizagem tem ocupado um considerável espaço na história das pesquisas em aprendizagem de segunda língua (ASL) (O'MALLEY; CHAMOT, 1990; COHEN, 1998; LIGHTBOWN; SPADA, 1999). Assim, poderíamos inferir que fatores como atitude linguística, motivação, estilos de aprendizagem, ansiedade e autoconfiança são elementos relevantes para a compreensão do domínio de uma língua estrangeira.

O grande problema de se lidar com DI nas pesquisas com ASL é que a maioria de suas variáveis-conceptuais está ligada ao complexo corpo teórico e investigativo da psicologia, situação que, segundo Dörnyei (2005), propicia uma incongruência teórica bastante comum. Nesse sentido; talvez a Hipótese do Filtro Afetivo de Stephen Krashen (1977-presente) ilustre bem essa inconsistência conforme discutiremos a seguir.

Como efeito parcial desse último quadro, tem-se uma quantidade enorme de vertentes sobre os estudos em DIs ao longo das últimas décadas (ver. BREEN, 2001; OXFORD; EHRMAN, 1993; SKEHAN, 1989). Não apenas porque esse tópico tem sido eleito como relevante e proveitoso, mas também por causa de modistas e/ou incipientes configurações teóricas, operadas entre linguística e psicologia, como sugeriremos adiante. 
v. 9 (2)

492-512

Possivelmente sob a influência de um desses movimentos de tendência da década de 70/80, período de auge do modelo virtual do bom aprendiz de língua (MACINTYRE; NOELS, 1994), tenha surgido a Hipótese do Filtro Afetivo de Krashen (1982), com suas três pilastras: ansiedade, autoconfiança e motivação.

Desde então a linguística aplicada, movida pelas alterações paradigmáticas de uma Scienza Nuova, dedica-se cada vez mais aos construtos capazes de explicar de forma mais complexa, porém não menos clara e definida, as variáveis individuais-sociais afetivas na ASL (ver. WILTON; STEGU, 2011). Paulatinamente, esse percurso tem implicado ênfase na (trans)interdisciplinaridade sistêmica e na ancoragem social das teorias e hipóteses, priorização de uma linguística popular voltada para o sujeito enquanto pessoa humana e não para modelos técnicos meramente teóricos e passíveis de testagem.

Diante desse panorama, este artigo procura discutir acerca do possível lugar que a hipótese de Krashen e o construto da motivação ocupam nas pesquisas recentes em linguística aplicada. Ao mesmo tempo, pretendemos apontar algumas relações dos dois elementos com o empírico, ao passo em que avaliamos seus respectivos potenciais de explicar fenômenos e indicamos outros de seus pontos mais questionáveis. Para tanto, empregamos aqui a metodologia de revisão crítica de referenciais teóricos, abordando o período que compreende o fim do século XX e o início deste século. Ademais, avaliaremos os tópicos em tela a partir das quatro funções básicas de uma teoria compreensão (seção 2), transformação (seção 3), predição e aplicação (seção 4) -, sendo as três primeiras apresentadas por Mclaughlin (1988) e a última aduzida por nós.

\section{Do poder explanatório das teorias}

Dentro dessa primeira função, compreensão, atentemos para o termo designativo da hipótese, Filtro Afetivo, que nos parece altamente metafórico, portanto, simbólico, inevidente e carente de descrição. Precisamos notar que o vocábulo filtro, por exemplo, advém da linguagem cotidiana e por isso mesmo possui uma série de aplicações/implicações nos mais diversos campos da atividade humana. Mclaughling (1988) aponta esse quadro como um sério obstáculo à compreensão de hipóteses científicas, o que pode ser minimizado mediante a argumentação concisa e menos alegórica. Krashen (1982), ao nosso ver, deixa implícito o que 
de fato pretende com o termo e, ao determinar sua condição como alto ou baixo, traz vocábulos que podem soar estranhos dentro do campo semântico-discursivo da figura em questão. Uma possível impressão suscitada através disso é a de que o filtro na verdade se trata de uma barreira que pode elevar-se ou não.

É claro que, mesmo na implicitude (pois pairam sobre tal hipótese sentidos bastante vagos), o leitor reconstrói contextualmente uma significação possível: filtro como dispositivo capaz de reter algo, selecionar; afetivo como sinônimo para emocional ou sentimental.

Observando-se mais atentamente o âmbito da compreensão, a hipótese do filtro afetivo parece apresentar certa inapropriação de conceitos emprestados da psicologia. Observe-se que a ideia do filtro afetivo encerra sob o mesmo sinete três constructos nada simples, quais sejam a ansiedade, a autoconfiança e a motivação. Este último sendo aqui mais enfocado em virtude da produtividade em pesquisas que gerou, sobretudo, na década de 1990.

Nesse sentido, aquele filtro krasheniano, pelas profusas implicações que acarreta, não poderia funcionar apenas mediante escalas de motivação, ansiedade e autoconfiança do aprendiz, antes disso, operaria como combinação do histórico de preferências e aversões que avalia a língua-alvo, a cultura à qual ela pertence e seus falantes nativos (ver. SCHUMANN, 1994).

Um considerável número de estudos tem abordado a relação das pilastras que sustentam a hipótese do filtro afetivo, como a ansiedade na ASL (DICKINSON, 1987), as funções da autoconfiança (KLEIN; KELLER, 1990; LAWRENCE, 1996) e a análise da motivação (MACARO et al., 2009; USHIODA, 2011). Ao que parece, nenhum deles esgotou seus respectivos objetos de foco, pelo contrário, parecem ter expandido ainda mais as fronteiras pelas quais se possam entender como uma língua é adquirida nesses distintos e específicos pontos de vista.

Diante disso, chama-nos a atenção o fato de que Krashen (1982) pretenda explicar um fenômeno, reunindo constructos tão amplos que estão ainda por serem explorados e melhor definidos. Pelos preceitos centrais de ciência, sua teoria deveria produzir sentido sobre um evento aparentemente caótico e inescrutado, porém Krashen parece unificar a complexidade sem demonstrar clareza suficiente ao fazê-lo, já que as relações entre as colunas de sua proposição são indeterminadas em seus escritos, até onde pudemos analisar. 
V. 9 (2)

492-512

Ora, é a precisão, e ao mesmo tempo a flexibilidade, dos componentes de uma hipótese que permitem ao pesquisador articular o funcionamento global na explicação de dado fenômeno ou conjuntos de fenômenos. É o percurso de combinação de todos os elementos da teoria que permite notar e entender o objeto de uma nova maneira (MCLAUGHLIN, 1988).

Notamos que os elementos usados por Krashen (1982) para construir sua hipótese estão em um domínio conceitual aparentemente bastante instável, impreciso e abrangente, o que por si só pode gerar uma grande dificuldade, conforme sugerimos anteriormente ao mencionar a tríade que constitui o filtro efetivo. Embora se perceba um notável interesse por parte do estudioso em desenvolver uma teoria detalhada e extensa, surge essa inadequação da falta de definição precisa quanto às conjecturas principais de sua hipótese.

Ora, a adequação definicional e o poder explanatório da teoria precisam estar bastante visíveis, caso contrário comprometer-se-á a correspondência dos conceitos da teoria com a realidade externa, isto é, com os fatos que ela pretende explicar. Observações e metáforas precisam ser descritas, analisadas, justificadas e experiências reproduzidas, para que assim se determine com maior acuidade os significados da teoria (GREGG, 1984).

Uma sugestão para atenuar o problema da vagueza dos termos teóricos seria o uso de definições operacionais (MCLAUGHLIN, 1988), isto é, a construção de sinonímia entre o conceito e as operações necessárias para mensurá-lo. Porém, não se percebe qualquer estratégia explícita como essa em prol da determinação conceitual do filtro afetivo ou mais especificamente de seus construtos subsidiários, que, reiteramos, são bastante amplos e indeterminados em Krashen (1982). Na verdade, da forma como demonstrados pelo linguista, esses construtos parecem possuir uma relação ainda mais remota com a experiência, não sendo baseados na referência a elementos observáveis, antes derivando seu sentido muito mais do todo teórico e da posição que ocupam em seu conjunto proposicional.

No entanto, uma situação distinta parece ocorrer em relação ao construto da motivação quando tratado por outros pesquisadores. Com abrangência abstrata relativamente menor que o filtro afetivo, esse conceito parece ter sido mais amplamente articulado e mais claramente definido ao longo de sua história no âmbito dos estudos em SL. Um de seus benefícios para a pesquisa é a aparente especificidade fenomenológica, 
fato que propicia a fomentação de hipóteses abstratas mais sólidas e passíveis de testagem. Esse ciclo de proposição e experimentação parece ter possibilitado uma expansão das relações da motivação com diversos aspectos da ASL, e isso clarifica ainda mais sua própria compreensão bem como a do processo que pretende explicitar.

Os estudos voltados para a motivação têm desenvolvido modelos sofisticados envolvendo não apenas aspectos psicológicos, como ressaltado em Krashen (1982), mas também sociais, contextuais e temporais (DÖRNYEI, 2001, 1994a, 1994b, 1998; CROOKES; SCHMIDT, 1991; WEN, 1997).

Em virtude das diversas perspectivas empregadas sobre esse constructo, há variadas definições para ele, o que aparentemente geraria confusões e mal-entendidos. Observamos que cada pesquisador poderia fazer uso de uma acepção distinta, possibilitando contradições improfícuas que apenas entravariam avanços no entendimento do fenômeno investigado. De outro modo, pode haver bastante similaridade entre as concepções, o que fomentaria um continuum cujos constituintes são indistinguíveis ou intercambiáveis. Além disso, a multiplicidade de sentidos terminológicos propiciaria contendas minimalistas, solipsistas ou sofismáticas.

Não obstante, todos esses vieses sobre a motivação contribuíram e contribuem para sua compreensão. De fato, as proposições de diferentes ângulos sobre o mesmo alvo não precisam se excluir mutuamente, embora possam estar relacionadas a distintas fases do processo comportamental motivado (DÖRNEY, 2003; PAIVA; NASCIMENTO, 2011).

No entanto, vista dentro do ambiente de pesquisas em motivação, percebemos que tal variedade de abordagens na verdade compartilha uma base comum, fato que parece possibilitar um entendimento recíproco entre os estudiosos do fator. Nessa base, encontram-se as ideias de consecução de um objetivo (imediato ou não, seja ele qual for), emprego de esforço, desejo (autocompelido ou não), e atitude favorável à realização de alguma atividade. Há também um empenho por parte dos teóricos em incluir a ideia de múltiplos objetivos, situação que tem dirigido a pesquisa para análise comportamental e cognitiva (PAIVA; NASCIMENTO, 2011).

Nota-se que essa última tendência de abordagem do complexo-motivação, através de multirrelações associadas às definições operacionais empregadas, elucida não apenas a ligação entre a teoria e 
V. 9 (2)

492-512 o que ela pretende abarcar, mas também a referência entre a hipótese e a realidade. Os mais precisos conceitos de variáveis motivacionais têmse definido a partir de instrumentos como a Bateria de Testes AtitudeMotivação, Questionário da Intensidade Motivacional (GARDNER; TREMBLAY, 1994), Instructional Materials Motivation Survey-IMMS, Motivational Delivery Checklist (KELLER, 1987), Escala da Motivação (WEN, 1997), Inventário de Estratégias para Aprendizagem de Línguas (OXFORD apud PAIVA, 1998), Questionário do Elemento Motivacional (SCHMIDT et al. apud DÖRNYEI, 1998), dentre outros.

Muitos podem argumentar que essas formas de visualizar a motivação são regidas por certo senso geral de um paradigma cognitivo positivista limitado, considerando que nelas a psicometria e os modelos computacionais abstratos caracterizam a observação dos processos mentais, aprendizagens e comportamentos. Nesse sentido, talvez tal indício incentive a apropriação e operacionalização dos valores da psicologia mediante maior precisão.

Embora essa notação sobre o paradigma (positivista) seja válida, os instrumentos de mensura anteriormente citados contribuíram para a abertura de uma compreensão menos determinista do fenômeno, supreendentemente. Assim, como sugerido por Dörnyei (apud MACARO et al., 2009), nas tessituras analíticas das pesquisas em ASL, as variáveis motivacionais têm sido cada vez mais tratadas como cambiantes entre sistemas cíclicos abertos e fechados, ou seja, dentro de uma crescente dinamicidade e complexidade.

Observamos que todo esse processo de referenciação em elementos práticos cognoscíveis reforça a adequação definicional e intensificam o poder explanatório do constructo da motivação. Ademais, mesmo nas limitações (por vezes positivistas) de suas operacionalizações, as possibilidades de conjunção dessa variável com inúmeras outras - entre 0,50 e 0,70 (ver. MACARO et al., 2009) - é bastante explorada, o que torna a explicitude da motivação bem mais consistente em comparação ao filtro afetivo.

\section{Das relações entre fenômenos e hipóteses}

Procedemos agora à percepção da hipótese krasheniana no âmbito da transformação, no qual se pode notar uma possível inconsistência empírica. Como já mencionado, novas proposições teóricas transformam a relação entre leis e fatos, habilitando o uso de 
dados para a aquisição de conclusões antes não evidentes. Contudo, Krashen parece não apresentar dados realmente eloquentes, o que torna sua propositura (no mínimo) bastante dubitável.

Ora, os dados usados nas explanações do filtro afetivo são obtidos de outros pesquisadores. Dados gerados a partir de metodologias cujos instrumentos específicos/especificados organizam uma impressão sobre o corpus, e consequentemente sobre a realidade. A consecução de dados não é um processo ideologicamente asséptico. Isso quer dizer que, ao gerálo, o pesquisador os marca com sua perspectiva teórica, seus objetivos de análise, seus instrumentos e todo seu aparato técnico-metodológico, além de outras assunções abstratas e concretas, implícitas e explícitas.

Assim, sendo tais configurações e posicionamentos tão dirigidos para determinadas metas, é evidente que duvidemos de como pode haver uma apropriação satisfatória delas em outra teoria absolutamente diversa, com implicações também distintas.

Ao citar tantos estudos, Krashen reforçaria uma proposição própria fundamentada no empírico, baseada num percurso analítico de dedução, inferência, enfim... abstração. O problema é que esse reforço, ao que parece, além de não ser suficientemente adequado à sua hipótese (pelas razões citadas nos parágrafos anteriores), soma-se à ausência de dados gerados especificamente para sua hipótese.

Talvez essas dificuldades de embasamento prático estejam relacionadas às normas de coerência interna e externa. O primeiro ponto polêmico e que merece atenção é esta afirmação de Krashen (não corroborada com evidências realmente significativas): "variáveis afetivas se referem diretamente à aquisição da língua [desenvolvimento natural, implícito/inconsciente], mas não à sua aprendizagem [desenvolvimento mais formal e explícito/consciente]" (KRASHEN; TERRELL, 1983, p. 92). O autor argumenta ainda que evidências mais contundentes seriam expostas mais tarde para corroborar essa dicotomia ou tricotomia afetividade-aquisição-aprendizagem.

Ora, muitos escritos contrariam Krashen nesse ponto (GREGG, 1984) e apontam para um continuum aquisição-aprendizagem-afetividade (USHIODA, 2011; DÖRNYEI, 2009) e não uma relação de tríade estanque em seus componentes. Krashen sugere que a afetividade não interfere na aprendizagem explícita e que esta não se transforma em aquisição.

Através dessa sua lógica, Krashen aparenta enfatizar a alta eficácia da simples exposição (aquisição) em contraste com a baixa efetividade do estudo gramatical (aprendizagem). Embora haja 
V. 9 (2)

492-512

contraexemplos sólidos (PARADIS, 1998), é observando essa insistência krasheniana e a apropriação da ideia de Chomsky que compreendemos melhor porque a afetividade, segundo ele, não influenciaria na aprendizagem. Se, substancialmente, a criança em estágio inicial não possui uma consciência cognitivo-linguística explícita, parece óbvio considerar que a afetividade tenha ação nula sobre ela. Porém, quando esse esquema é reaplicado na adolescência ou na fase adulta, há que se obter conclusões minimamente distintas.

A adolescência é o período da erupção emocional e da hipersensitividade, por exemplo, o que pode indicar uma potencialização das variáveis afetivas que assim agiriam mesmo sobre o desenvolvimento consciente da língua. Além disso, levando-se em conta a crescente precocidade afetiva nas crianças, notada como óbvia no mundo contemporâneo globalizado, duvidamos que esse filtro realmente lhes seja inoperante.

Considerando esses últimos parágrafos, seria conveniente concluir que: ora, se na criança o filtro não opera e na adolescência atinge seu ápice, poderíamos pressupor então que ele tende a desaparecer na ocorrência da fase adulta ou talvez encontrar um ponto de maturação/ equilíbrio (cf. GREGG, 1984). Obviamente, essa é uma especulação, pois Krashen (1981; 1982; 1985; KRASHEN; TERRELL, 1983) não indica tal visão em sua hipótese, embora seja possível deduzi-la de seu argumento do "quanto mais jovem em ASL melhor". Diante de tantas incertezas, não é de se admirar que, na hipótese do filtro afetivo, tenham sido deixados absolutamente implícitos o como surge e o porquê surge o filtro afetivo apenas na puberdade.

Outro ponto que tende a ser bastante obscuro entre fenômeno e hipótese é como esse filtro funciona; que modus operandi se emprega na seleção de determinadas partes da língua e que partes são essas, por que são retidas. Aliás, o próprio conceito de insumo compreensível usado para abordar tais partes dificilmente pode ser mensurado pela implícita equação $i+1^{1}$.

Ao imaginar como a motivação se integra a todo esse panorama, somos levados a concordar com Long e Laser-Freeman (1991, p. 247): "para obter conteúdo empírico, Krashen necessitaria especificar que variáveis individualmente afetam, ou em que combinações o fazem, e

${ }^{1}$ Esta equação é originária da hipótese do Input, na qual "i" designaria a interlíngua e "+ 1" indicaria o estágio seguinte ou alvo a ser atingido no processo de aquisição (ver. KRASHEN, 1985). 
em que níveis, servem para 'elevar o filtro'"'. Diante disso, questionamos novamente: se apenas um dos três principais aspectos do filtro estiver positivo, como a motivação, por exemplo, será suficiente para "baixar o filtro"? Que aspectos devem operar positivamente (em que grau) para que o filtro contribua na aquisicao de uma língua?

Krashen (1982) introduz vários estudos para (meta)analisar a ligação entre motivação e autoimagem, mas suas perscrutações não parecem expor claramente possíveis encaminhamentos para as dúvidas do parágrafo anterior. Nesse segmento, sua argumentação mais explícita é a de que a motivação integrativa - aquela referente ao desejo de aprender/adquirir uma língua para integrar-se com êxito à comunidade da língua alvo - é necessária. Quanto a isso também paira outra incerteza: não seria possível adquirir/aprender uma língua sem querer ser como o falante nativo?

Não obstante essa notação marginal, Krashen tem sido acusado de tornar sua hipótese uma concepção insociável - talvez em face de certa influência de Lennenberg, Chomsky e/ou Freud - e insuficientemente flexível (MITCHELL; MYLES, 2004). De fato, a ausência de observações e exames atentos à conexão motivação-atmosfera social limitam bastante as explanações de Krashen. Poderíamos até mesmo afirmar que essa ausência tende a debilitar a relação de sua proposição com os fenômenos que pretende explanar.

Por outro lado, o constructo da motivação enquanto objeto de pesquisa é acusado da mesma limitação (MITCHELL; MYLES, 2004), mas parece permitir-se avançar um pouco além das fronteiras da psicometria intrapessoal e da díade biocognitiva. Para percebê-lo, basta adentrar teorias como Goal-Theory (LATHAM; LOCKE, 2002), Zona de Desenvolvimento Proximal (VYGOTSKY, 1987), Hierarquia das Necessidades Motivacionais (ALDERFER, 1972), e principalmente a Teoria do Desenvolvimento Socioemocional (ERIKSON; SULLIVAN apud AMES; AMES, 1989), cuja propositura assegura que as relações sociais e interpessoais são fundamentais para que a motivação lidere uma aprendizagem cooperativa.

Ademais, a base prática do constructo-motivação parece ser bem mais consistente se comparada à do filtro afetivo. São quase que incontáveis os estudos que abordam a relação da motivação com dezenas de outros fatores e aspectos do desenvolvimento linguístico (ver. USHIODA, 2011; DÖRNYEI, 2005; DÖRNYEI; CSIZÉR, 2002; PAIVA; NASCIMENTO, 2011; SADE, 2003). 
V. 9 (2)

492-512

maio-ago

2019

Poderíamos usar muitas páginas citando estudos propositalmente engendrados para explicar a motivação nos mais variados e persuasivos contextos, já que a maioria maciça daqueles encontrados nessa breve análise são estudos originais. Em outras palavras, não foram emprestados de outros pesquisadores, pois não consistem em metaestudo, como ocorre em Krashen (1982). Observamos que tal diversificação de contextos situa o constructo em um panorama cada vez maior, com cada vez mais relações, de forma que se delineiam, a cada passo, novos fios de uma imensa rede conceptual.

O fato de a motivação vir sendo abordada de modo tão profuso propicia uma relativa flexibilidade e adaptabilidade de sua cognoscência. Assim, pode-se erigir uma ampla plataforma empírica mais consistente contra a qual será árduo argumentar, considerando não apenas o número de evidências obtidas, mas também o raio de alcance delas e as multiqualitativas articulações pelas quais o constructo foi tratado.

Com efeito, esses estudos expansionistas tendem a afastar a supralógica unifocal da abordagem naturalista acerca do ensino, da qual a hipótese de Krashen (1982; KRASHEN; TERRELL, 1983) parece depender em essência formal e em teor.

Quanto ao constructo motivacional, os próprios instrumentos de mensuração e os modelos anteriormente citados, não obstante suas limitações, contribuem de modo significativo para a geração de dados mais adequados aos objetivos e proposituras teóricas das pesquisas a ele relacionados.

Contrariando o que Krashen permite vislumbrar, Bremer et al. (1996), por exemplo, demonstram que, para migrantes adultos como Berta, aprendizes de língua adicional, a SL só estará disponível em face de fatores afetivo-sociais poderosos, capazes de constituir-se em substrato para a produção de ímpeto ou energia motivacional (BREMER et al., 1996). A resposta emocional de Berta em relação à língua aponta para um continuum da motivação intrínseca e extrínseca (FISHER, 1990), do contexto social e noção afetiva.

\section{Do potencial investigativo e da aplicabilidade das teorias}

Por fim, refletimos sobre a hipótese de Krashen e o constructo da motivação sob a perspectiva da predição (MCLAUGHLIN, 1988) e da aplicação, ou implicações práticas. Nesse primeiro ponto, e repensando o que temos afirmado até aqui, somos compelidos a admitir que a 
validade produtiva da hipótese do filtro é imensamente questionável, sobretudo, em virtude de problemas com a coerência das explanações de Krashen (1982). Somam-se a essas questões os estudos não propositados aduzidos e reinterpretados (GREGG, 1984), sua tendência em fazer vastas afirmações sobre uma base empírica insuficiente ou rarefeita (TAYLOR, 1984) e sua propensão em afastar as evidências contrárias para as notas de rodapé de seus escritos (TAKALA, 1984).

Note-se que todas essas dificuldades parecem incidir sobre a capacidade da proposição do autor em predizer com certa precisão o curso do desenvolvimento linguístico (MCLAUGHLIN, 1988), bem como parece prejudicar o fornecimento de pistas para estudos que articulem os princípios por ele suscitados.

As pesquisas voltadas para a ASL, assim como outras teorias mais produtivas ou passíveis de serem conjecturadas em novas investigações, não precisam fornecer todas as respostas, incluir todas as variáveis possíveis, evidentemente. Porém, se forem convenientemente mais focadas, limitadas e específicas, talvez consigam potencializar mais solidamente seus alcances.

Aoqueparece, aspublicações/pesquisasmaisrecentes, abordando ou utilizando a hipótese de filtro afetivo, na maioria das vezes se dedicam a desconstruí-la (ZAFAR, 2009) - basta observar a quantidade de críticas a Krashen até aqui aduzidas -, a utilizá-la como comparativo marginal de análise (DOUGLAS, 2007; CHAMETZKY, 2013) e referência geral-histórica para manuais de ensino (COLOMBO; FURBUSH, 2009; WALTERS; FREI, 2007; MISHMAN, 2005), ou a obter dela aspectos ou prismas de reflexão bastante limitativos/alusivos (SCHULZ, 1991; GARCÍA-CARBONELL et al., 2001). A maioria dos estudos que mencionam o filtro afetivo, no entanto, não se constroem fidedignamente em relação à hipótese de Krashen, mas em referência a uma pletora de DIs psicológicas/linguísticas que estão para muito além da proposição do estadunidense (McCANN et al., 1986; ROBERTON, 2011), tendendo inclusive para a abordagem da motivação como aspecto central (POUPORE, 2014; SITI; MELOR, 2014; DOVER, 2012; CHANG, 2005; HYLAND, 2004), a autoestima e/ou autopercepção e/ou crenças (LIN, 2008).

Entre os estudos mencionados, McCann e seus colegas (1986) se mostram um interessante exemplo para revisão. Priorizando uma abordagem quantitativa e psicométrica, os pesquisadores procuram corroborar a hipótese do filtro afetivo. Apesar de seu esforço, as conclusões a que eles chegam não são suficientes ou conclusivas para 
V. 9 (2)

492-512

maio-ago

2019

confirmar a hipótese propriamente, mas apontam para a relevância de seus componentes (motivação, autoconfiança e ansiedade). Assim, não apenas neste estudo, mas em todos os demais citados nesta seção, não é exatamente o design teórico de Krashen que recebe particular apoio, mas essas DIs que o intelectual referencia em sua propositura, considerada uma precursora na área de aspectos individuais em ASL. Claro, trata-se de conclusões preliminares, pois seria necessário perscrutar mais fontes para atestar com maior segurança o que indicamos aqui como tendência.

Por outro lado, ao atentarmos para o constructo da motivação, averiguamos que este tem circulado por diversos domínios científicos de pesquisa, e a produção associada às suas funções e relevância é praticamente inominável. Como já sugerido, ao passo em que esse multipertencimento clarifica sua compreensão, parece também direcionar investigações com um considerável potencial de produtividade prática.

Temos em mente que não se trata, stricto sensu, de uma propositura organizada e aparelhada abstratamente ou desprovida de dimensão primariamente empírica, e é justamente isso que autoriza tantas contextualizações e abordagens distintas: é um constructo maleável. Entretanto, por consequência disso, pode haver usos indiscriminados dele, bem como sua aparente vulgarização.

Ainda assim, à medida que recebe novos tratamentos, o constructo pode agregar propriedades das teorias mais prestigiadas que o concebem. Então, ao ser interpelado no âmbito de pesquisas em ASL, talvez seja necessário cautela e diligência em delimitá-lo bem e evitar confusões ou vaguezas.

Uma observação mais cuidadosa na história dos estudos em ASL mostra que o ápice do constructo da motivação (década de 1990) e seus ecos nos últimos anos são prova cabal de seu inquestionável potencial de produtividade prática (DÖRNYEI, 2005). Ao contrário da maioria das pesquisas relacionadas à hipótese do filtro afetivo (se é que realmente existam muitas delas), os trabalhos científicos com a motivação parecem explorá-la pela evocação de incontáveis outras teorias e ambientes, obtendo-se dela mais ricos e extensos significados e relações, além de encaminhamentos para novos estudos.

Quanto à aplicabilidade de ambos, constructo da motivação e hipótese de Krashen, seria prudente concluir que a teoria nem sempre se traduz em ação. Transposições na tríade hipótese-prática-metodologia (se assim podem ser chamados esses árduos processos) são requeridas para que se vislumbre a "aplicação" de uma propositura abstrata em ASL. 
Não obstante esse fato, considera-se que a boa teoria deve ser falsificável para que assim seja testável (LONG apud MITCHELL; MYLES, 2004). Isso quer dizer que, embora ela não possa ser imediatamente usada para conduzir à prática, seus pressupostos devem ser suficientemente claros (detalhando o que vai ou não ocorrer), e ao mesmo tempo passíveis de serem observados em experimentos.

Ora, já foi há muito notado que a falsificabilidade da hipótese de Krashen (1982) encontra-se comprometida porque não se autodetermina com a clareza necessária. Em consequência disso, parece que não se percebe a presença de variáveis comprováveis na prática, tampouco instrumentalização ou operacionalização de conceitos que torne isso possível.

Perante esse quadro, fica difícil acreditar que haja possibilidades sólidas de aplicação da hipótese do filtro afetivo. Prova disso é que neste brevíssimo estudo não se encontraram pesquisas relevantes e consistentes sobre o assunto, embora implicações sugestivas para a prática tenham sido tomadas a partir do esforço de alguns professores (SCHÜTZ, 2017).

Aduzimos a seguir algumas ações em sala da aula que talvez façam funcionar alusivamente o célebre filtro afetivo: a) fornecer instruções não apenas orais, mas também escritas com a finalidade de evitar qualquer pressão e propiciar a realização mais tranquila da tarefa solicitada; b) propiciar a realização de atividades interessantes, inovadoras, relevantes para o aprendiz; c) lidar com materiais ou insumos adequados ao nível de conhecimento linguístico do aprendiz proporcionado-lhe, no entanto, a oportunidade de avançar, oferecendolhe algo além do que ele já sabe; d) garantir que tais insumos retratem o máximo possível a realidade social de utilização da língua-alvo; e) permitir bate-papo descontraído em sala e até mesmo brincadeiras ou piadas não-didáticas; f) evitar ao máximo a 'correção' gramatical explícita do aprendiz, sobretudo, em público; g) proporcionar ao aprendiz momentos de comunicação em SL nos quais se oculte sua identidade; h) não forçá-lo a falar, ao contrário, deixá-lo absolutamente livre para usar a língua-alvo quando se sentir preparado para tal; i) ênfase máxima nas atividades que envolvem a compreensão oral ou escrita.

É evidente que essas são apenas ideias inspiradas pela propositura de Krashen (1982), não fruto da solidez do embasamento teórico-prático ou daquelas árduas transposições metodológicas. Trata-se de indicações até mesmo instintivas, em relação a muitas das quais nem seria necessário haver uma hipótese krasheniana (MCLAUGHLIN, 1988). 
V. 9 (2) 492-512 maio-ago 2019

Já as implicações práticas da motivação são tão diversas quanto os tratamentos que recebe nas pesquisas científicas. Outra diferença em relação à hipótese do filtro é que as sugestões do constructo da motivação em ASL, embora pareçam advir de estudos específicos e propositados, são mais abrangentes e permitem diversas ações para a consecução do mesmo fim. Talvez porque não sejam só produto do mero instinto.

Dörnyei (1994a; 1994b), por exemplo, sugere - como meio de consolidar a motivação na sala de aula: a) desenvolvimento da autoconfiança (autoeficácia) do aluno; b) redução da atmosfera de ansiedade excessiva (já que em níveis controlados ela pode não ser prejudicial); c) encorajar os alunos a estabelecer metas pessoais/grupais atingíveis; d) aumentar a atratividade do conteúdo do curso - e. g., enriquecimento social e cultural do material linguístico.

O mesmo autor sugere ainda os Dez Mandamentos para a Motivação dos Aprendizes de Línguas (apud COWIE; SAKUI, 2011, p. 223):

(1) estabelecer um exemplo pessoal; (2) criar uma atmosfera agradável; (3) apresentar tarefas adequadamente; (4) desenvolver um bom relacionamento com os estudantes; (5) aumentar a autoconfiança linguística dos estudantes; (6) tornar as aulas interessantes; (7) promover a autonomia do aprendiz; (8) personalizar o processo de aprendizagem; (9) aumentar o direcionamento para metas; (10) familiarizar os aprendizes com a cultura da língua alvo².

Oxford e Shearin (1996) também oferecem sugestões práticas para professores no âmbito da motivação. De acordo com os autores, professores podem identificar o porquê de os estudantes estarem estudando uma nova língua, podem também moldar as crenças dos estudantes acerca do sucesso e do fracasso em aquisição de L2, e podem ainda ajudar estudantes a melhorar a motivação ao mostrar que a aprendizagem de L2 pode ser um desafio mental empolgante, um potencializador de carreira, um instrumento de conscientização cultural. Ademais, professores podem auxiliar aprendizes a elaborar metas individualizadas e gozar de recompensas também personalizadas, o que pode gerar um senso mais extensivo e notável de autoeficácia, autodirecionamento e autoavaliação (OXFORD; SHEARIN, 1996).

\footnotetext{
${ }^{2}$ 1. Set a personal example; 2 . Create a pleasant atmosphere; 3 . Present tasks properly; 4. Develop a good relationship with students; 5. Increase students' linguistic selfconfidence; 6. Make classes interesting; 7. Promote learner autonomy; 8. Personalize the learning process; 9. Increase goal orientedness; 10. Familiarize learner with the target language culture.
} 
Com efeito, é possível afirmar que praticamente todas as ações sugeridas e listadas até então derivam-se de aspectos muito mais concernentes ao constructo da motivação em si do que ao filtro afetivo. Assim, poder-se-ia afirmar de antemão que a motivação é um fator muito mais influente na prática de ASL do que os outros dois pilares da hipótese de Krashen (ansiedade e autoconfiança).

Por esse viés, temos que considerar também que a motivação, ansiedade e autoconfiança que o aprendiz traz consigo para dentro do ambiente de aprendizagem são bastante cambiantes e dependem também da idade, da atmosfera familiar, inter alia. Agora imaginemos esse background em um contexto escolar de reforço negativo, por exemplo, no qual testes e provas representem uma ameaça. Ora, ao não atingir os níveis esperados, o aprendiz pode frustrar-se e o sentimento de fracasso pode ser poderoso para desanimá-lo e reduzir seu engajamento, através de um gama de processos e múltiplos fatores para muito além do filtro ou da motivação em si.

As atividades em sala de aula, a despeito de que possam ser encaradas como trabalho, precisam gerar algum tipo de satisfação, propiciar comunicação significativa e mais autêntica. Talvez a recompensa, o respeito, os valores democráticos de gestão do espaço escolar, o ser ouvido/considerado produzam efeitos muito positivos nas atitudes do aprendiz em relação ao processo de desenvolvimento linguístico.

\section{Considerações finais}

Nossa meta aqui foi demonstrar que, conquanto Krashen seja um clássico influente e de grande impacto nos estudos em ASL, sua pesquisa apresenta problemas de formulação, predição, correspondência ao fenômeno e outros de coerência interna. Não encontrando em suas proposições um valor de fato heurístico sobre o qual se possa invocar contextos persuasivos e gerar mais hipóteses, os pesquisadores tendem a centrar-se em outras proposições potencialmente mais produtivas. Assim, eles parecem priorizar muito mais a interação entre DIs e ASL do que o filtro afetivo enquanto modelo teórico-metodológico, dada a incipiência de seu estabelecimento.

Para o constructo da motivação, a realidade parece ser um pouco diferente. Primeiro, porque não se trata de uma propositura sistemática e explanatória, mas apenas um conceito altamente maleável cujos usos em pesquisa são inúmeros. Além disso, levando-se em conta 
v. 9 (2)

492-512

outros fatores individuais afetivos em ASL, é inegável e essencial seu papel na aprendizagem de línguas. De certo, essa situação favorece a alta produtividade de estudos sobre esse constructo e a fomentação de diversas novas teorias e hipóteses a partir dele.

\section{Referências}

ALDERFER, C. Existence, relatedness, \& growth. New York: Free Press, 1972.

AMES, C.; AMES, R. Research in motivation in education. San Diego: Academic Press, 1989.

BREEN, M. Learner contributions to language learning: New directions in research. Harlow: Longman, 2001.

BREMER, K. et al. Achieving understanding: Discourse in intercidtural encounters. Harlow: Longman, 1996.

CHAMETZKY, B. Generalizability and the Theory of Offsetting the Affective Filter. The Grounded Theory Review, vol. 12, n. 2, p. 1-9, 2013.

CHANG, M.-M. Applying self-regulated learning strategies in a web-based instruction - an investigation of motivation perception. Computer Assisted Language Learning, vol. 18, n. 3, p. 217-230, 2005.

COHEN, A. D. Strategies in learning and using a second language. New York: Longman, 1998.

COLOMBO, M; FURBUSH, D. Teaching English language learners: content and language in middle and secondary mainstream classrooms. Thousand Oaks: Sage, 2009.

COWIE, N.; SAKUI, K. Crucial but Neglected: English as a Foreign Language Teachers' Perspectives on Learner Motivation. In: MURRAY, G.,

CROOKES, G.; SCHMIDT, R. W. Motivation: reopening the research agenda. Language Learning, vol. 41, n. 4, December, p. 469-512, 1991.

DICKINSON, L. Self instruction in language learning. Cambridge: Cambridge University Press, 1987.

DÖRNYEI, Z. Motivation and motivating in the foreign language classroom. Modern Language Journal, vol. 1, n. 78, p. 273-284, 1994a.

DÖRNYEI, Z. Understanding L2 motivation: On with the challenge! Modern Language Journal, vol. 1, n. 78, p. 515-523, 1994 b.

DÖRNYEI, Z. Survey Article: Motivation in second and foreign language learning. Language Teaching, vol. 1, n. 31, p. 117-135, 1998.

DÖRNYEI, Z. Teaching and Researching Motivation. Harlow, England: Longman, 2001. 
DÖRNYEI, Z. Attitudes, orientations, and motivation in language learning: Advances in theory, research, and applications. Language Learning, vol. 3, n. 53, p. 32, 2003.

DÖRNYEI, Z. The Psychology of the Language Learner Individual Differences in Second Language Acquisition. London: Lawrence Erlbaum Associates Publishers, 2005.

DÖRNYEI, Z. The relationship between language aptitude and language learning motivation: individual differences from a Dynamic Systems Perspective. In: MACARO, E.; VANDERPLANK, R.; MURPHY, V. A. (orgs.). Continuum Companion to Second Language Acquisition. London: Continuum, 2009.

DÖRNYEI, Z.; CSIZÉR, K. Some dynamics of language attitudes and motivation: Results of a longitudinal nationwide survey. Applied Linguistics, v. 23, n.4, p. 421-462, 2002.

DOUGLAS, B. H. Principles of Language Learning and Teaching. $5^{\mathrm{a}}$ ed. New York: Pearson Education, 2007.

DOVER, Y. Affective filter influence on students' initiating the B.A. English major at the Universidad Nacional, Chorotega Branch in Nicoya, Guanacaste, Costa Rica. Revista Ensayos Pedagógicos, vol. 6, n. 1, p. 169-188, 2012.

FISHER, Robert. Teaching Children to Think. London: Nelson Thornes, 1990.

GARCÍA-CARBONELL, A. et al. Simulation/gaming and the acquisition of communicative competence in another language. Simulation \& Gaming, vol. 32, n. 4, p. 481-491, 2001.

GARDNER, R.; TREMBLAY, P. On motivation: measurement and conceptual considerations. Modern Language Journal, vol. 78, n. 4, p. 524-527, 1994.

GREGG, K. Krashen's Monitor and Occam's razor. Applied Linguistics, ed. 5, n. 79 p. 100: 1984 .

HYLAND, F. Learning autonomously: contextualizing out-of-class English language learning. Language Awareness, vol. 13, n. 1, p. 180-202, 2004.

KELLER, J. IMMS: Instructional materials motivation survey. Florida State University: 1987.

KLEIN, J.; KELLER J. Influence of student ability, locus of control, and type of instructional control on performance and confidence. Journal of Educational Research, vol. 83, n. 3, p. 140-46, 1990.

KRASHEN, S. Principles and practice in second language acquisition. Oxford: Pergamon, 1981.

KRASHEN, S. Principles and practice in second language acquisition. Oxford: Pergamon, 1982.

KRASHEN, S. The Input Hypothesis: issues and implications. New York: Longman, 1985. 
V. 9 (2)

492-512

KRASHEN, S.; TERRELL, T. The natural approach: Language acquisition in the classroom. London: Prentice Hall Europe, 1983.

LATHAM, G.; LOCKE, E. Building a Practically Useful Theory of Goal Setting and Task Motivation. The American Psychologist, vol. 1, n. 57, p. 707-709, 2002.

LAWRENCE, D. Enhancing self-esteem in the classroom. London: PCP Ltd., 1996.

LIGHTBOWN, P.; SPADA, N. How languages are learned? New York: Oxford University Press, 1999.

LIN, G. Pedagogies proving Krashen's theory of affective filter. Hwa Kang Journal of English Language \& Literature, vol. 14, n. 1, p. 113-131, 2008.

LONG, M.; LARSEN-FREEMAN, D. An introduction to Second Language Acquisition Research. London: Longman, 1991.

MACARO, E. et al. A Compendium of Key Concepts in Second Language Acquisition. London: Continuum International Publishing Group, 2009.

MACINTYRE, P.; NOELS, K. The good language learner: A retrospective review. System, vol. 1, n. 22, p. 269-280, 1994.

McCANN, L. D. et al. Communication apprehension and second language acquisition among Vietnamese and Mexican immigrants: A test of the Affective Filter Hypothesis. Communication Research Reports, vol. 3, n. 1, p. 33-38, 1986.

MCLAUGHLIN, B. Theories of second language learning. London: Edward Arnold, 1988.

MISHMAN, F. Designing authenticity into language learning materials. Bristol: Intellect, 2005.

MITCHELL, R.; MYLES, F. Second Language Learning Theories. $2^{\mathrm{a}}$ ed. London: Hodder Arnold, 2004.

O'MALLEY, J.; CHAMOT, A. Learning strategies in second language acquisition. New York: Cambridge University Press, 1990.

OXFORD, R.; SHEARIN. Language learning motivation in a new key. In: R. L. Oxford (org.). Language learning motivation: pathways to the new century. Honolulu: NFLRC, 1996, p. 155-87.

OXFORD, R.; EHRMAN, M. Second language research on individual differences. Annual Review of Applied Linguistics, vol. 1, n. 13, p. 188-205, 1993.

PAIVA, V.; NASCIMENTO, M. (org.). Sistemas Adaptativos Complexos. Linguagem e Aprendizagem. Campinas: Pontes, 2011.

PAIVA, V. Estratégias individuais de aprendizagem de língua inglesa. Letras e Letras. vol. 14, n. 1, jan./jul., p. 73-88, 1998. 
PARADIS, M. The other side of language: Pragmatic competence. Journal of Neurolinguistics, vol. 11, n. 1-2, p. 1-10, 1998.

POUPORE, G. The influence of content on adult L2 learners' task motivation: an interest theory perspective. The Canadian Journal of Applied Linguistics, vol. 17, p. 69-90, 2014.

ROBERTON, T. Reducing affective filter in adult English language learning classrooms. Dissertação de Mestrado, The Evergreen State College, Olympia, 2011.

SADE, L. Querer é poder, querer e poder, querer sem poder: a motivação para o aprendizado de inglês na escola pública sob uma perspectiva semiótica social. 2003. 240 f. Dissertação (Mestrado em Linguística Aplicada) - Faculdade de Letras, Universidade Federal de Minas Gerais, Belo Horizonte, 2003.

SCHULZ, R. Second language acquisition theories and teaching practice: how do they fit? Modern Language Journal, vol. 75, n. 1, p. 17-26, 1991.

SCHUMANN, J. Where is cognition? Emotion and cognition in second language acquisition. Studies in Second Language Acquisition, vol. 1, n. 16, p. 231-242, 1994.

SCHÜTZ, R. Stephen Krashen's Theory of Second Language Acquisition. English Made in Brazil Website: 2017. Disponível em <http://www.sk.com.br/ sk-krash.html >. Acesso em 18 de maio de 2019.

SITI, S.; MELOR, M. Attitudes and motivation towards learning English among FELDA school students. Australian Journal of Basic and Applied Sciences, vol. 8, n. 1, p. 1-8, 2014.

SKEHAN, P. Individual differences in second language learning. London: Edward Arnold, 1989.

TAKALA, S. A review of Language Two by Heidi Dulay, Marina Burt and Stephen Krashen. Language Learning, vol. 34, n. 1, p. 157-174, 1984.

TAYLOR, G. Empirical or intuitive? A review of the Natural Approach: language acquisition in the classroom by Stephen D. Krashen and Tracy D. Terrell. Language Learning, vol. 34, s/n, p. 97-105, 1984.

USHIODA, E. Motivating Learners to Speak as Themselves. In: Murray, G., Gao, X.; Lamb, T. Identity, Motivation and Autonomy in Language Learning. Bristol: Multilingual Matters, 2011.

VYGOTSKY, L. Mind in Society. Cambridge: Harvard University Press, 1987.

WALTERS, J.; FREI, S. Managing classroom behavior. Huntington Beach: Shell Education, 2007.

WEN, X. Motivation and Language Learning with Students of Chinese. Foreign Language Annals, vol. 1, n. 30, p. 235-250, 1997.

WILTON, A.; STEGU, M. Bringing the 'folk' into applied linguistics. Association Internationale de Linguistique Appliquée (AILA) Review, New York, NY, v. 24, n.1, p. 1-14, jan./jul. 2011. 
V. 9 (2)

492-512 maio-ago 2019
ZAFAR, M. Monitoring the 'Monitor': a critique of Krashen's five hypotheses. The Dhaka University Journal of Linguistics, vol. 2, n. 4, p. 239-146, 2009. 